\title{
Wildflower (Hyoscyamus reticulatus) causes QT prolongation
}

\author{
Aslan $\mathrm{S}^{1}$, Cakir Z $\mathrm{Z}^{1}$, Emet $\mathrm{M}^{1}$, Aksakal E², Akoz A³, Uzkeser $\mathrm{M}^{1}$ \\ Department of Emergency Medicine, Ataturk University, Medical School, Erzurum, Turkey. \\ sahinaslan29@hotmail.com
}

\begin{abstract}
Introduction: In the environment, there are hundreds of poisonous and injurious plants with a wide variety of toxicity. Among all plants with anticholinergic effect, Hyoscyamus reticulatus is a species whose clinicopathological effects have been poorly described in literature. The paper is especially aimed at drawing attention to the possibly fatal syndrome of prolonged QT, as well as to clinical and laboratory changes in six members of a single family poisoned with this plant.

Cases: Six female patients aged from 19 to 49 presented to our emergency room with a suspicion of being poisoned after having ingested a plant known as 'the mad axe plant' (Hyoscyamus reticulatus). At least one of anticholinergic symptoms including flushing, mydriasis, dry mouth and tachycardia was present in all of the patients. In addition, different levels of agitation were observed in four of the patients. A euphoric emotional state was present in two patients. The corrected QT distances were found to be prolonged in three of the patients. Discussion and conclusion: Based on economical, social and cultural reasons, it is a very common habit in our country, especially in our region in spring and summer months, to consume some plants growing spontaneously in rural areas as food. Intoxication with Hyoscyamus reticulatus is a plant poisoning that is poorly described in literature. Its classical symptoms are predominantly anticholinergic. Although it is commonly self-limited and can be corrected with close observation and supportive treatments, it should be kept in mind that the prolongation of QT interval can accompany the symptoms of poisoning with this plant (Tab. 1, Fig. 3, Ref. 19). Full Text in PDF www.elis.sk.

Key words: emergency, wildflower, poisoning, QT prolongation, Hyoscyamus reticulates.
\end{abstract}

In the environment, there are hundreds of poisonous and injurious plants with a wide variety of toxicity. In general, children ingest these plants intentionally as food source, or accidentally, thus their poisoning is mainly unintentional. Plant poisonings are most commonly seen in adults, in whom they are most frequently accidental. Nevertheless, cases of plant ingestion with the intention of committing suicide may also be encountered. At the same time, both children and adults yield an increase in the incidence of these poisonings. This is brought about by their increasing preference for herbal drugs (1). Although there are no clear statistical data in our country, according to the statistics gathered by the American Association of Poison Control Centers, plants are the fourth most common reason for poison center notification and they account for 5 to 10 percent of all calls received (2-4).

Hyoscyamus reticulatus is a plant of the Solanaceae family, and its roots, leaves and fruits, similarly to those of Hyoscyamus niger and Atropa belladonna, contain alkaloids hyoscyamine and scopolamine (5). Oral ingestion of Hyoscyamus reticulatus may develop into many different types of clinical pictures ranging from

${ }^{1}$ Department of Emergency Medicine, Ataturk University, Medical School, Erzurum, Turkey, ${ }^{2}$ Department of Cardiology, Ataturk University, Medical School, Erzurum, Turkey, and ${ }^{3}$ Regional Research and Training Hospital, Erzurum, Turkey

Address for correspondence: S. Aslan, MD, Ataturk University, School of Medicine, Department of Emergency Medicine, 25090, Erzurum, Turkey. Phone: +4423166333/1461, Fax: +4423166340_ an asymptomatic condition, through mild nausea, to life-threatening pathologies as depression of respiration.

This manuscript reports clinicopathological effects of intoxication with an anticholinergic plant Hyoscyamus reticulatus in six members of a single family. Of all clinical and pathotlogical alterations in these patients, we aimed at drawing attention to the life-threatening prolongation of QT interval.

\section{Cases}

Six female members of one family aged from nineteen to forty-nine were admitted to our emergency room with a suspicion for being poisoned after having ingested a kind of plant growing in rural areas. Based on the assertion of the relatives of patients, as well as upon examination of plant samples they had brought, it was determined that the plant in question was Hyoscyamus reticulatus known in our region as 'mad axe plant' (Fig. 1). At least one of anticholinergic symptoms including flushing, mydriasis, dry mouth and tachycardia was present in all of the patients (Fig. $2 \mathrm{a}, \mathrm{b}, \mathrm{c})$. In addition, different levels of agitation were observed in four of the patients. A euphoric emotional state was present in two patients. The basic clinical and laboratory findings in these patients, and the amounts of plant they had ingested are presented in Table 1. In three of the six patients, the corrected QT interval calculated using the Bazzet formula $(\mathrm{QTc}=\mathrm{QT} /(\sqrt{\mathrm{RR}}))$ in $\mathrm{D}_{2}$ derivation of 12 lead ECG was prolonged. The ECG of the patient with the longest QT interval is shown in Figure 3. The blood pseu- 


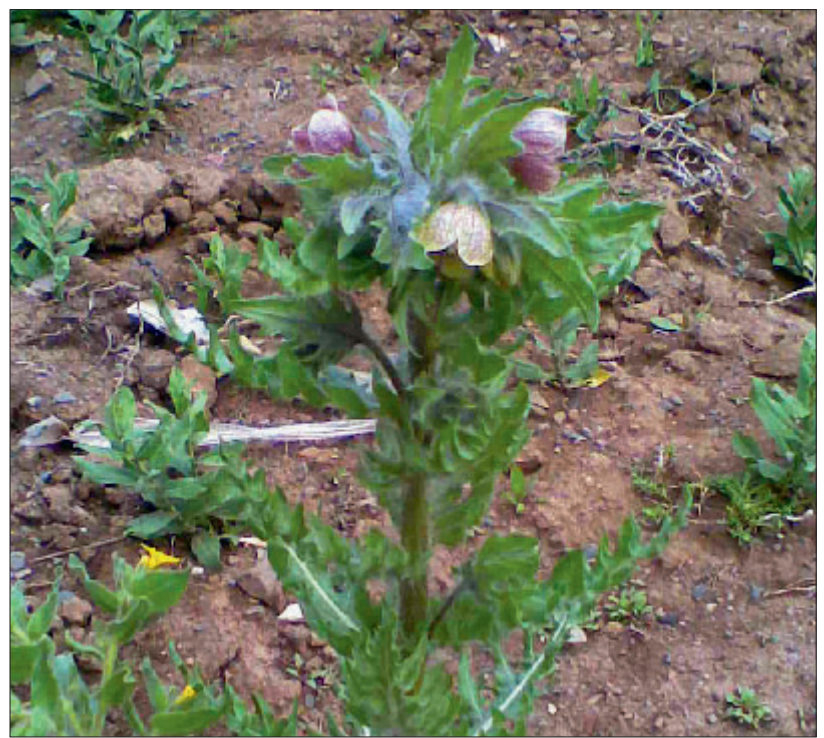

Fig. 1. Photo of Hyoscyamus reticulatus.

docholinesterase levels were found to be normal in all patients, the fact of which excluded organophosphate poisoning. Nasogastric tube, gastric lavage and supportive treatments due to symptoms (hydration, oxygen support and IV diazepam to agitated patients) were applied to all patients in the first three hours. Since the specific antidote Physostigmine could not be obtained, it could not be given to the three patients suffering from severe cholinergic symptoms. After recovery, which took 48 hours on average, the patients were discharged from emergency clinic.

\section{Discussion}

In our country, especially in our region in spring and summer months, it is a very common habit to consume plants growing wild in rural areas as food. This habit has many economical, social and cultural reasons. Hyoscyamus reticulatus is a plant wildly growing in rural areas in almost all regions of our country and in all seasons. It has some features similar to those of Hyoscyamus niger, which belongs to the same family. Since it may be confused with various other plants that can be ingested by adults and children, the poisoning with this plant is encountered commonly, especially in spring months (6). The ingestion, regardless whether intentional or accidental, can seriously deteriorate the psychophysical state or even cause death (7). As opposed to the abundance of cases of poisoning by Hyoscyamus niger that have been reported to date, there is only one case series of poisoning with Hyoscyamus reticulatus described in literature, namely that by Urkin et al (8). In the present manuscript, a case of six patients poisoned with Hyoscyamus reticulatus, and cured with supportive treatment is reported.

The main alkaloids in Hyoscyamus reticulatus are atropine (hyoscyamine) and scopolamine (hyoscine). This explains the clinical picture of combined stimulation and depression of the brain. Described as Central Anticholinergic Syndrome (CAS), it is characterized by mental impairment, recent memory disturbances, hallucinations, hyperpyrexia, ataxia, excitement, drowsiness, coma, dry skin and flushing, tachycardia, mydriasis, and absence or decrease in bowel movements (7-9). More than one of these anticholinergic symptoms were present in all of our cases, while weakness and dizziness were the most common ones. As to anticholinergic symptoms, mydriasis and dry mouth were found in four of the six patients, while agitation and euphoria in three of them (Tab. 1, Fig. 2 a, b, c). The intensity of anticholinergic symptoms and signs was considered proportional to the amount of consumed plant.

The prolonged QT syndrome is a clinically heterogenous syndrome that may occur due to drugs and genetic or non-genetic pathological conditions, and develop with cardiac repolarization defects (10). The main pathology in both genetic and acquired forms is the dysfunction in ion channels of the cardiomyocyte membrane (11). The causes of prolonged QTc include congenital (long QT syndrome) or acquired cardiac diseases (ischemic heart disease, cardiomyopathy, hypertension, myocarditis, valvular diseases), cerebrovascular diseases (hemorrhage, stroke), systemic diseases (renal, hepatic), electrolyte abnormalities (hypokalemia, hypomagnesemia, hypocalcemia), and effects of the drugs (12, 13). Although the prolongation of QT interval due to toxins has not been reported, it can be suggested that they may prolong the QT interval through similar mechanisms as drugs.

The prolongation of QT interval may cause different types of ventricular arrhythmia. The most common among these is the Torsades de Pointes (14). The risk increases significantly, especially in women if the QT interval exceeds $600 \mathrm{msec}(10,14,15)$. All of our patients were female and in three of them, the QT interval was longer than $440 \mathrm{msec}$. However, ventricular arrhythmia was not reported in any of the patients on follow-up. The QT prolon-
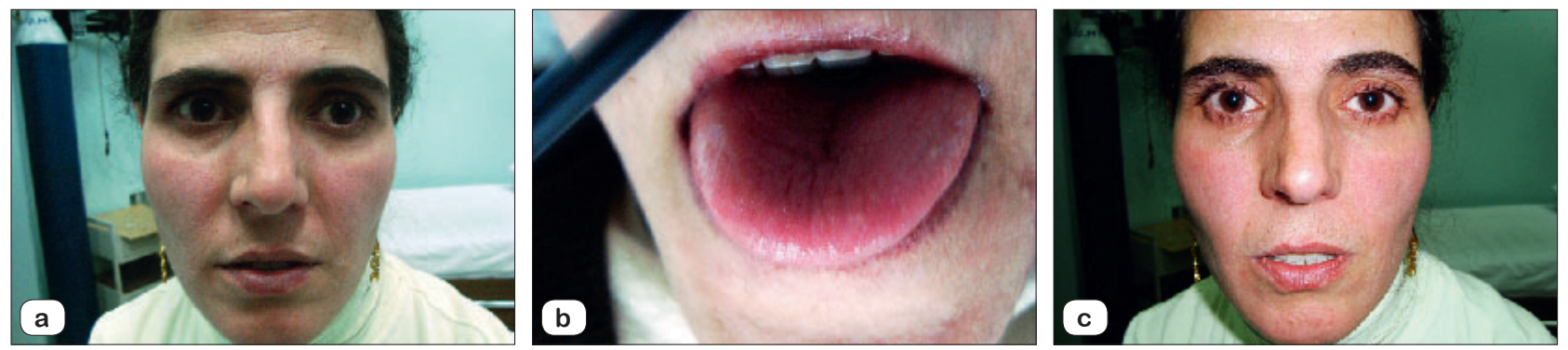

Fig. 2. Anticholinergic symptoms of the patients: a - flushing of face, $b$ - dry mouth, $c$ - mydriasis. 
Tab. 1. Basic clinical and laboratory characteristics of the patients.

\begin{tabular}{|c|c|c|c|c|c|c|}
\hline Characteristics & 1th Patient & 2nd Patient & 3th Patient & 4th Patient & 5thPatient & 6th Patient \\
\hline Age, sex & $49, \mathrm{~F}$ & $44, \mathrm{~F}$ & $35, \mathrm{~F}$ & $36, \mathrm{~F}$ & $19, \mathrm{~F}$ & $35, \mathrm{~F}$ \\
\hline Amount & 3-4 trunks & $2-3$ trunks & 1 trunk & $2-3$ trunks & 4-5 trunks & $2-3$ trunks \\
\hline Dry mouth & + & + & - & - & + & + \\
\hline Dizziness & + & + & - & + & + & + \\
\hline Agitation/euphoria & - & $+/+$ & + & + & $+/+$ & - \\
\hline Nausea & - & - & + & + & + & + \\
\hline Vomiting & - & - & - & + & - & + \\
\hline Heart rate & 119/min. & $123 / \mathrm{min}$ & 101/min. & $109 / \mathrm{min}$ & $133 / \mathrm{min}$ & $80 / \mathrm{min}$ \\
\hline QT duration & 440 msec. & 463 msec. & $363 \mathrm{msec}$. & $363 \mathrm{msec}$. & $463 \mathrm{msec}$ & $408 \mathrm{msec}$. \\
\hline Mydriasis & + & + & - & - & + & + \\
\hline Temperature & $37.5^{\circ} \mathrm{C}$ & $37.5^{\circ} \mathrm{C}$ & $37.0^{\circ} \mathrm{C}$ & $38.0^{\circ} \mathrm{C}$ & $37.5^{\circ} \mathrm{C}$ & $37.4{ }^{\circ} \mathrm{C}$ \\
\hline Flushing & - & - & - & + & + & - \\
\hline GCS & 13 & 14 & 15 & 15 & 14 & 13 \\
\hline Diplopia & - & + & - & - & + & + \\
\hline
\end{tabular}

F - female, min - minutes, msec - miliseconds, GCS - Glascow Coma Scale

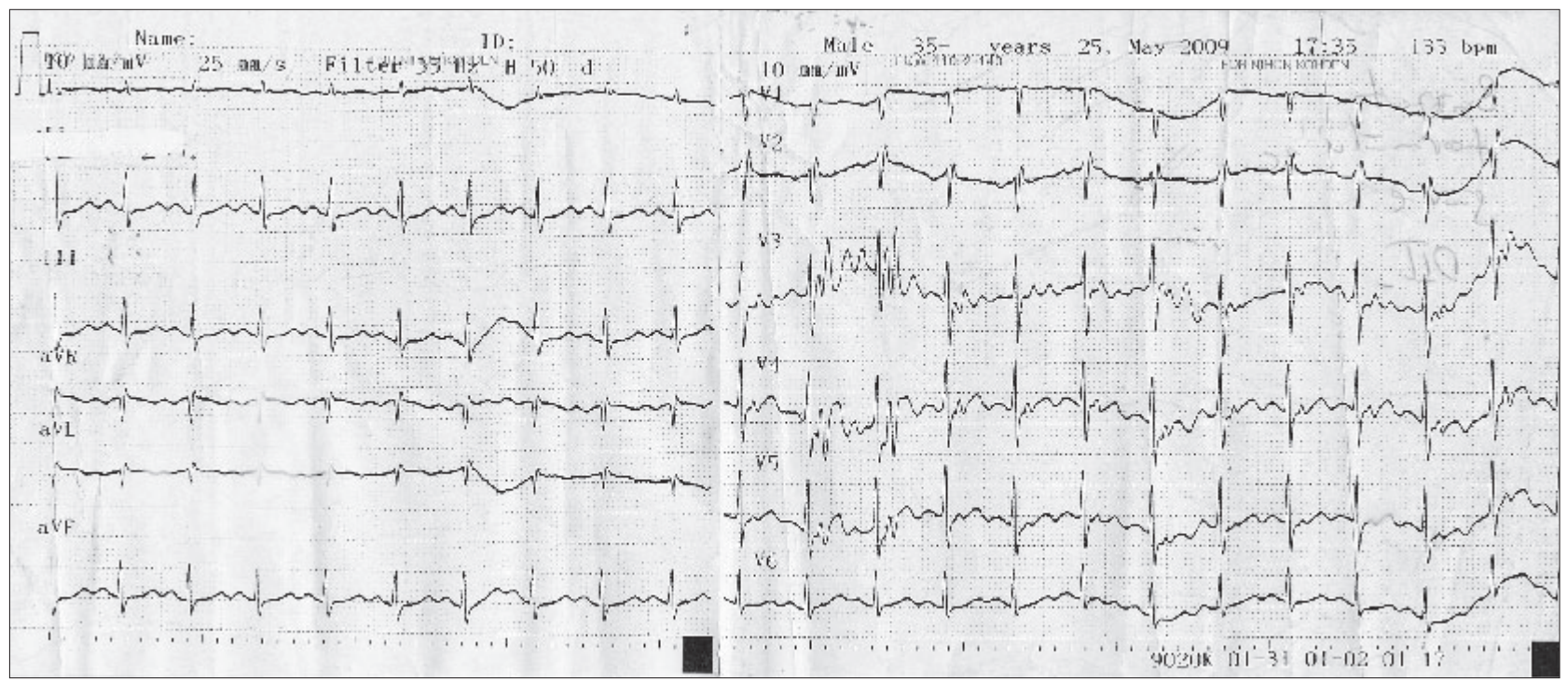

Fig. 3. ECG of the patient with the longest QT interval.

gation in our patients may be considered to be caused by alteration of $\mathrm{K}$ channel permeability due to one of the toxins. The only study dealing with Hyoscyamus reticulatus intoxication in literature is that of Urkin et al., who did not mention anything about QT prolongation. ${ }^{8}$ Despite the fact that in literature there are many studies dealing with intoxication with Hyoscyamus niger, being from the same family as Hyoscyamus reticulatus, and with other plants with anticholinergic effects, none of these studies report QT prolongation. Therefore, we do not know if this symptom is specific for Hyoscyamus reticulatus or a general pathophysiological effect of this group. Larger clinical and experimental studies on this topic are warranted.

Gastric lavage, active charcoal application $(1 \mathrm{~g} / \mathrm{kg})$, and repetition following emergency stabilization if necessary are recommended for patients with CAS signs (16). Gastric decontamination and active charcoal application were performed in all of our patients. It was reported in a study that supportive treatment among patients with CAS development was sufficient in $20 \%$, intensive care treatment was necessary in $20 \%$, and that the mortality rate was $0.16 \%$. In the same study, it was empahasized that the mortality rate was higher in patients with central nervous system symptoms (17). Supportive treatment should include following up the patients with regard to life-threatening symptoms of hyperpyrexia and convulsion, and to diminish the agitations. Intravenous hydration and peripheral cooling applications can be utilized in the treatment of hyperpyrexia, while benzodiazepines can be used in the treatment of acute agitations and convulsions. Physostigmine should be used in serious cases with dysrrhythmia, evident hypertension, uncontrolled hyperpyrexia, convulsions and coma (18, 19). All of our patients were discharged after complete recovery accomplished only by supportive treatment being administered for 48 hours. Despite the indication for the use of physostigmine in three cases with severe CAS symptoms and QT prolongation, we could not use physostigmine since we could not purchase it. 
333-336

The fact of completing the cure of all patients with only supportive treatment can be attributed to early gastric decontamination.

In conclusion, we would like to state that Hyoscyamus reticulatus intoxication is a plant poisoning with classic anticholinergic symptoms predominance that has been forgotten in literature. It can be corrected through close observation and supportive treatment. It should be kept in mind that the prolonged QT interval can be an accompanying symptom of this plant poisoning.

\section{References}

1. Krenzelok EP, Jacobsen TD. Plant exposures: A national profile of the most common plant genera. Vet Hum Toxicol 3 1997; 9: 248.

2. Litovitz TL, Klein-Schwartz W, Rogers GC et al. 2001 Annual report of the American Association of Poison Control Centers Toxic Exposure Surveillance System. Am J Emerg Med 2002; 20: 391.

3. Mrvos R, Krenzelok EP, Jacobsen TD. Toxidromes associated with the most common plant ingestions. Vet Hum Toxicol 2001; 43: 366.

4. Lawrence RA. Poisonous plants: When they are a threat to children. Pediatr Rev 1997; 18: 162.

5. Orbak Z, Tan H, Karakelleoglu C, Alp H, Akdag R. Hyoscyamus niger (henbane) poisonings in the rural area of east Turkey. AUTD 1998; 30: $145-148$.

6. Erkal H, Özyurt Y, Arikan Z. Yaşli hastada Henbane (Hyoscyamus Niger) sonrasi antikolinerjik sendrom. Turk J Geriatr 2006; 9: 188-191.

7. Vidović D, Brecić P, Haid A, Jukić V. Intoxication with henbane. Lijec Vjesn. 2005; 127: 22-23.

8. Urkin J, Shalev H, Sofer S, Witztum A. Henbane (Hyoscyamus reticulatus) poisoning in children in the Negev. Harefuah. 1991; 120: 714-716.
9. Al-Shaikh AM, Sablay ZM. Hallucinogenic plant poisoning in children. Saudi Med J 2005; 26: 118-121.

10. Allan WC, Timothy KW, Vincent GM et al. Long QT syndrome in children: the value of rate corrected QT interval and DNA analysis as screening tests in the general population. J Med Screen 2001; 8: 173-177.

11. Elming H, Sonne J, Lublin HK. The importance of the QT interval: a review of the literature. Acta Psychiatr Scand 2003; 107: 96-101.

12. Gongadze N, Kezeli T, Antelava N. Prolong QT interval and "torsades de pointes" associated with different group of drugs. Georgian Med News 2007; 153: 45-49.

13. Altmann D, Eggmann U, Ammann P. Drug induced QT prolongation. Wien Klin Wschr 2008; 120 (5-6): 128-135.

14. Elming H, Sonne J, Lublin HK. The importance of the QT interval: a review of the literature. Acta Psychiatr Scand 2003; 107: 96-101.

15. Witchel HJ, Hancox JC. Familial and acquired long QT syndrome and the cardiac rapid delayed rectifier potassium current. Clin Exp Pharmacol P 2000; 27: 753-766.

16. Albertson TE, Derlet RW, Foulke GE, Minguillon MC, Tharratt SR. Superiority of activated charcoal alone compared with ipecac and activated charcoal in the treatment of acute toxic ingestions. Ann Emerg Med 1989; 18: 56-59.

17. Brown DV, Heller F, Barkin R. Anticholinergic syndrome after anesthesia: a case report and review. Am J Ther 2004; 11: 144-153.

18. Stefanek J, Dufincova J, Vychytil P, Holmes S. Mystery of mydriatic pupils. Vnitr Lek 2000; 46: 808-810.

19. Ridder WP, Klimek M, Rupreht J. Physostigmine for the immediate treatment of a patient with the central anticholinergic syndrome induced by cocaine cut with atropine. Ned Tijdschr Geneeskd 2005; 149: 1701-1703.

Received February 12, 2010. Accepted January 27, 2013. 